\title{
Nio and Ag@Nio Nanomaterials for Enhanced Photocatalytic and Photoluminescence Studies: Green Synthesis Using Lycopodium Linn.
}

\author{
K. R. Basavalingaiah ${ }^{1}$, Udayabhanu ${ }^{2}$, S. Harishkumar ${ }^{3}$, G. Nagaraju ${ }^{4}$ and Chikkahanumantharayappa ${ }^{5^{*}}$ \\ ${ }^{1}$ Department of Science, Government Polytechnic, Tumkur, Karnataka, India \\ ${ }^{1 \& 5}$ Department of Physics, Vivekananda Degree College, Bengaluru, Karnataka, India \\ ${ }^{2,3 \& 4}$ Energy Materials Research Laboratory, Department of Chemistry, \\ Siddaganga Institute of Technology, Tumkur, Karnataka, India \\ ${ }^{3}$ Department of Pharmaceutical Chemistry, Kuvempu University, Post-Graduate Centre, Kadur, Karnataka, India \\ *Corresponding Author \\ E-Mail: chrayappa@gmail.com
}

\begin{abstract}
NiO and Ag-NiO nano particles were prepared using Lycopodium extract as a fuel via solution combustion synthesis (SCS) at $500{ }^{\circ} \mathrm{C}$. From the PXRD, FTIR, UV-DRS studies the synthesized NPs were characterized. The morphologies of the prepared NPs were studied by SEM and TEM analysis. The synthesized NPs were tested for photocatalytic and photoluminescence studies. The PXRD data indicated that the synthesized nanoparticles belong to cubic phase structure and space group Fm-3m. The FTIR spectrum of NiO exhibited the absorption bond at $427 \mathrm{~cm}^{-1}$ is associated to $\mathrm{Ni}-\mathrm{O}$ vibration band. The SEM data revealed that agglomeration was obtained. $\mathrm{NiO}$ and $\mathrm{Ag}-\mathrm{NiO} \mathrm{Nps}$ were taken for determine the photocatalytic activity study on methylene blue dye, the results indicated that Ag-NiO NPs exhibited promising photocatalytic activity. This is due to occurrence of $\mathrm{Ag}$ particles on the $\mathrm{NiO}$ material, which makes the catalyst more sensitive. Furthermore, a photoluminescence study for $\mathrm{NiO}$ and Ag-NiO was studied.
\end{abstract}

Keywords: $\quad$ Lycopodium, Ag-Nio, Photocatalytic, Photoluminescence

\section{INTRODUCTION}

Industrial dyestuff contain one of the largest groups of organic compounds that lead to discoloration of water and cause great loss of aquatic life. The elimination of these colors and other organic materials is a priority for ensuring a safe and clean environment [1]. Over the last decades, photo catalysis has attracted special attention as an economic and environmentally safe option for solving energy and pollution problems [2]. Among various semiconductors showing photocatalytic activity, wide band gap semiconductors such as $\mathrm{TiO}_{2}, \mathrm{ZnO}$, etc. bear tremendous hope in helping ease the energy and environment crisis through effective utilization of solar energy based on photovoltaic and water-splitting devices [3, 4]. Unfortunately, their wide band-gaps do not allow the utilization of visible light, which limit their practical applications. Therefore, it is imperative to develop new kinds of photo catalysts with high activities under visible light in view of the efficient utilization of solar energy.

Nickel oxide $(\mathrm{NiO})$ is an important transition metal oxide with cubic lattice structure. It has attracted increasing attention owing to potential use in a variety of applications such as: catalysis [5], battery cathodes [6, 7], gas sensors [8], electrochromic films [9] and magnetic materials [10, 11]. It can also be extensively used in dye sensitized photocathodes [12]. It exhibits anodic electrochromism, excellent durability and electrochemical stability, large spin optical density and various manufacturing possibilities [13].

Nanostructured $\mathrm{NiO}$ has a wide range of applications as a ptype semiconductor with a stable wide band gap (3.6-4.0 eV) [14], although bulk $\mathrm{NiO}$ is an antiferromagnetic insulator [15]. Nano-sized $\mathrm{NiO}$ is also used in alkaline batteries [16], electrochemical capacitors [17]. Ag is wellknown for its intense interactions with visible-light via the resonance of the oscillations of the free electrons within the particles [18], and is considered as a relatively cheap noble metal.

Photo excited electrons in the conduction band (CB) of a semiconductor can be transferred to the noble metals, which act as electron sinks due to the Schottky barrier at the metal-semiconductor interface, while the holes can remain on the semiconductor surface[19,20]. The recombination of electrons and holes can therefore be prolonged, and the photocatalytic activity will be improved [21]. In addition, the Plasmon resonance of noble metal nanoparticles (NPs) is expected to enhance absorption of incident photons, which will enhance the photocatalytic efficiency of the semiconductors [22]. Hence, that the $\mathrm{NiO}$ nanoparticles are modified with $\mathrm{Ag}$ particles may exhibit an enhanced photocatalytic activity.

Herein the synthesis of $\mathrm{NiO}$ and $\mathrm{Ag}-\mathrm{NiO}$ nanoparticles via combustion method using lycopodium extract as a fuel. The prepared NPs were characterized using powder X-ray diffraction (PXRD), Fourier transform infrared analysis (FTIR), UV-diffused reflectant spectrum (UVDRS), scanning electron microscopy (SEM) and transmission electron microscopy (TEM) of the NiO NPs. Photocatalytic activity of $\mathrm{NiO}$ was examined by photodegradation of methylene blue (MB) under visible light illumination and photoluminescence (PL) study was also carried out. 


\section{EXPERIMENTAL ANALYSIS}

A. Synthesis of NiO and Ag-NiO Nps from Lycopodium: In a typical experiment, synthesis of NiO NPs from Lycopodium linn using solution combustion method. The stochiometric ratios of $\mathrm{Ni}\left(\mathrm{NO}_{3}\right)_{2}$ and $\mathrm{AgNO}_{3}$ were mixed with Lycopodium, which acts as Fuel. The Nickel nitrate and Lycopodium extract $(5,10,15$ and $20 \mathrm{~mL})$ were added in a crucible and stirred thoroughly with magnetic stirring for $\sim 10 \mathrm{~min}$. After, the formed homogenous solution was kept in muffle furnace maintained at $500{ }^{\circ} \mathrm{C}$ for 5 min to get product. For synthesis of $\mathrm{Ag}-\mathrm{NiO}$, The synthesis of $\mathrm{NiO}-\mathrm{Ag}$ nano composites (NiO-Ag-1\%; NiO-Ag-3\%; NiO-Ag-5\%; NiO-Ag-7\%) using $10 \mathrm{~mL}$ Lycopodium (optimized fuel).

B. Characterization: The synthesized nanoparticles were characterized by using powder X-ray diffractometer (Rigaku smart Lab). FTIR (Bruker-alpha) to analyse metal oxide bond stretching frequencies. The UV- DRS spectrum of the NPs was measured using UV-Visible spectrophotometer (Lab India-Diffuse reflectance spectra and Cary 60 Agilent technologies-Absorbance spectra). The morphologies of the prepared nanoparticles were scanned using Scanning Electron Microscopy (Hitachi-7000 Table top). Shape and size of the $\mathrm{NiO}$ crystallites was determined using transmission electron microscope (JEOL 3010). Photoluminescence studies were recorded using fluorescence spectrophotometer Agilent technology Cary Eclipse).

C. Photo Catalytic Activity: Photo-Reactor "Heber" was purchased from Chennai. The photocatalytic reactor consists of a medium pressure mercury vapor lamp $(\lambda \max =365$ $\mathrm{nm}, 250 \mathrm{~W})$ in a jacketed quartz crystal tube. The heat caused by the lamp was removed from cold water by continuous circulation throughout the jacket. The tube has an inside diameter of $2.3 \mathrm{~cm}$, with an outer diameter of 2.7 $\mathrm{cm}$ diameter, which is $37 \mathrm{~cm}$ long, $100 \mathrm{ml}$ capacity and is placed around the lamp.

The gap between the mercury lamp and the quartz tube containing pollutant was $6 \mathrm{~cm}$. The uniform distribution of catalytic particles throughout the solution was achieved using air pump [23]. The solution was allowed for constantly bubbled in the dark for 30 minutes to ensure the organization of an adsorption-desorption equilibrium between the photocatalyst and MB previous to irradiation of light source. The suspension $2 \mathrm{~mL}$ was withdrawn from the reactor over 30 minutes intervals. Centrifuge the solution using spin win micro centrifuger to remove the NiO NPs from the mixture. The dye concentration of left over aqueous solution was measured using UV-Vis spectrophotometer at $664 \mathrm{~nm}$. The \% degradation of the MB is calculated using the equation (i)

$$
\% \text { of degradation }=\frac{\mathrm{Ci}-\mathrm{Cf}}{\mathrm{Ci}} \times 100 \cdots \cdots \cdots(i)
$$

Where $\mathrm{Ci}$ initial and $\mathrm{Cf}$ final dye concentrations in ppm. The photocatalytic experiment was repeated by changing different parameters such as concentration of dye, catalytic load, $\mathrm{pH}$ variation, catalyst recycling, etc.

\section{RESULTS AND DISCUSSION}

A. PXRD Study: The PXRD patterns of NiO nanoparticles are represented in Fig.1. From the XRD data indicated that $\mathrm{NiO}$ NPs has cubic phase structure and space group Fm-3m (no.225) resembles with the standard JCPDS card number 1-1239 [24]. No extra peaks were found in the pattern which indicates that purity of the samples. The average crystallite size was measured to be $14.27 \mathrm{~nm}$ for $\mathrm{NiO}$ and $14.19 \mathrm{~nm}$ for $\mathrm{Ag}-\mathrm{NiO}$, respectively.
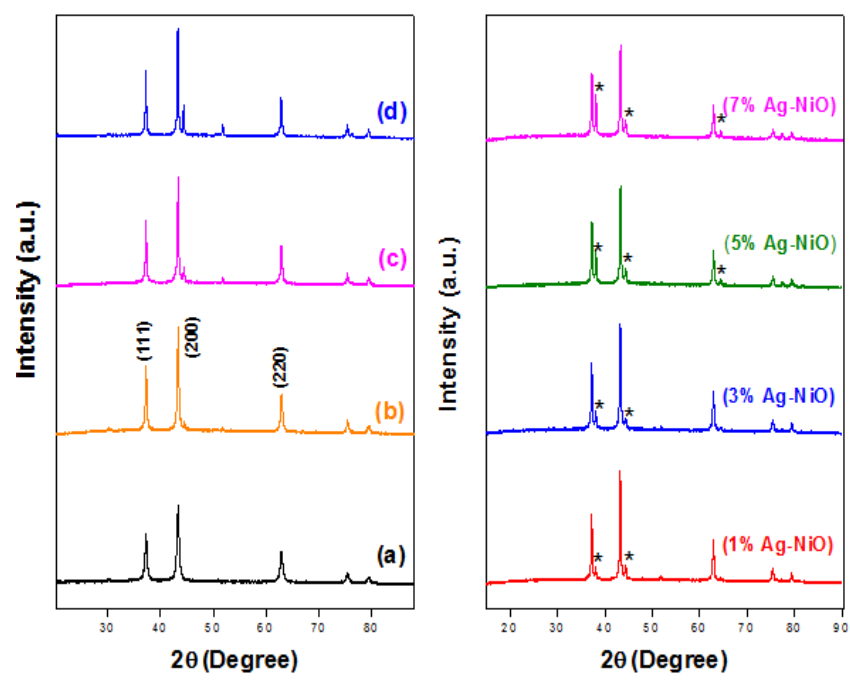

Fig. 1 Powder XRD patterns of the $\mathrm{NiO}$ and $\mathrm{Ag}-\mathrm{NiO}$ nanoparticles

B. FTIR Study: The FTIR spectra of $\mathrm{NiO}$ and Ag-NiO nanomaterials were recorded between the ranges of 4000 to $400 \mathrm{~cm}^{-1}$ as shown in Fig 2. Additionally, characteristic bands of $\mathrm{NiO}$, which include the $\mathrm{Cu}-\mathrm{O}$ symmetric and asymmetric stretching vibrations at $407 \mathrm{~cm}^{-1}$ were also observed [25]. The broad peak at 3435 and $1632 \mathrm{~cm}^{-1}$ is due to the stretching and bending vibrations of $-\mathrm{OH}$, which is due to the absorbed moisture on the surface of the catalyst $[26,27]$.

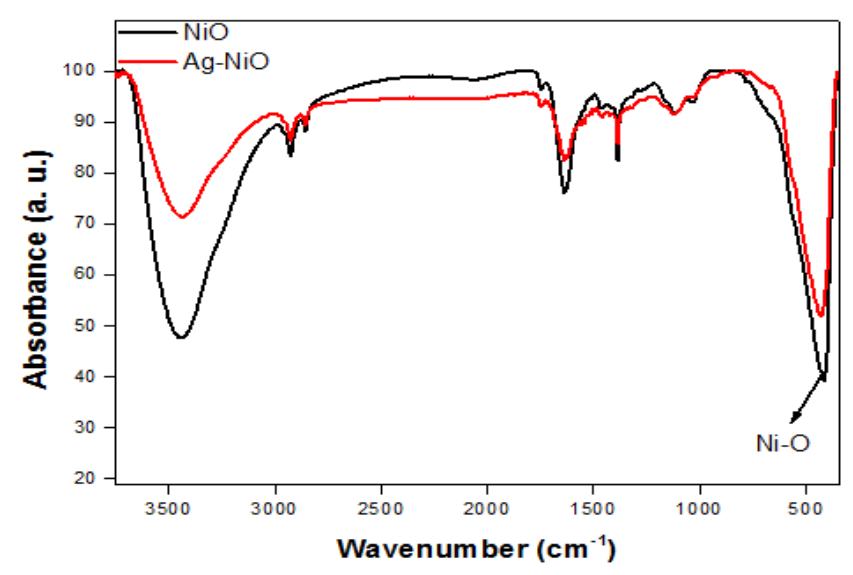

Fig. 2 FTIR spectra of $\mathrm{NiO}$ and $\mathrm{Ag}-\mathrm{NiO}$ Nanoparticles 
C. UV-Visible Diffuse Reflectance Studies: (UV-DRS): Fig. 3 shows the UV-Visible spectra of $\mathrm{NiO}$ and $\mathrm{Ag}-\mathrm{NiO} \mathrm{NPs}$ synthesized via combustion method using lycopodium extract as a fuel. The spectra demonstrate with absorption band shown nearly at 300 to $350 \mathrm{~nm}$. Due to electron transfer from valence band to conduction band. The calculated Eg values were found to be $3.79 \mathrm{eV}$ and $3.75 \mathrm{eV}$ for $\mathrm{NiO}$ and $\mathrm{Ag}-\mathrm{NiO} \mathrm{NPs}$ respectively [28].

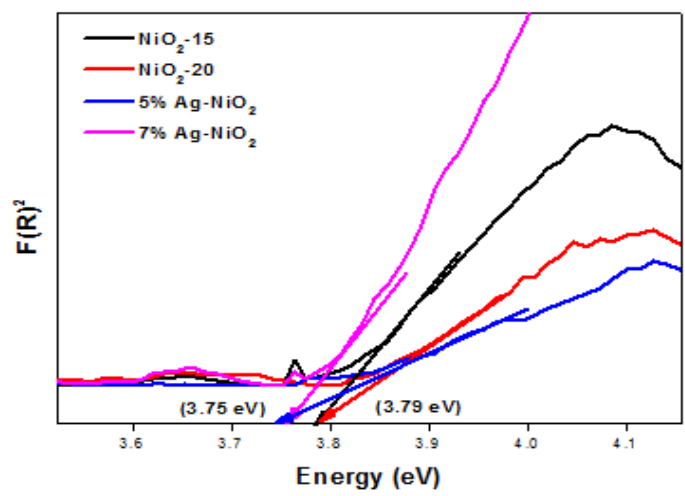

Fig. 3 UV-DRS spectrum of $\mathrm{NiO}$ and Ag-NiO NPs

D. Scanning Electron Microscopy (SEM) Studies: Fig. 4 (a, b) represents SEM images of the compound $\mathrm{NiO}$ and Fig. 4 (c, d) for Ag- NiO NPs synthesized via combustion method using lycopodium extract as a fuel. The particles are looking like homogenous distribution which is formed by the agglomeration of NPs.

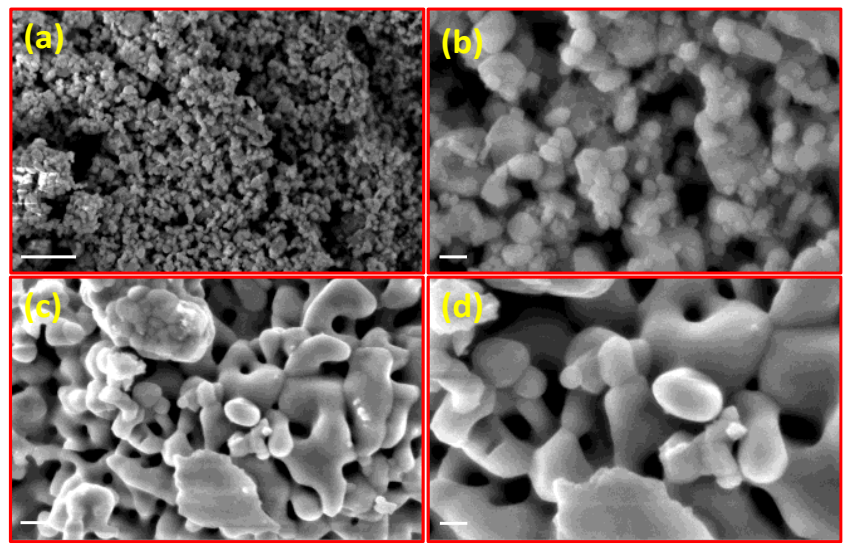

Fig. 4 SEM images of $\mathrm{NiO}$ nanomaterials (a) and (b), and Ag-NiO nanomaterials (c) and (d)

E. Transmission Electron Microscopy (TEM) Studies: Fig. 5 shows the TEM images, HR-TEM.images and SAED pattern of synthesized Ag- NiO NPs using Lycopodium linn. as a fuel via combustion method. From the TEM images (Fig. 5a, b) we can clearly observe the fine distribution of silver $(\mathrm{Ag})$ on band like nanomaterials. In the Fig.5c the distributed silver (black colored dots) on $\mathrm{NiO}$ acquired spherical shape with size of 4.5 to $14.3 \mathrm{~nm}$. The sizes of $\mathrm{NiO}$ materials were observed 42 to $76 \mathrm{~nm}$. For NiO, (Fig. 5c) the d-spacing value is $0.15 \mathrm{~nm}$, which belongs to (220) plane. From the SAED pattern, (Fig. 5d) it is confirmed as a polycrystalline in nature. The planes at (111), (200) and (220) planes having highest intensity in XRD and which are matched with bright circular fringes in SAED pattern.

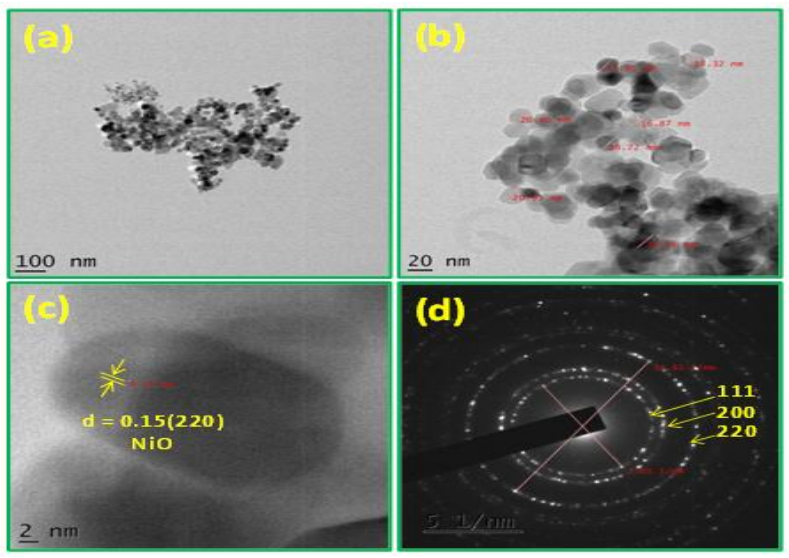

Fig. 5 TEM images (a,b), HR-TEM images (c) and SAED pattern(d) of $\mathrm{NiO}$ nanomaterials

\section{PHOTOCATALYTIC DEGRADATION OF NiO AND AG-NiO NPs}

Under light radiation, the semiconductor absorbs photons of energy greater than the band gap of semiconductors and then creates electrons and holes in the valence and conducting band. If the charge carriers don't accompanied, then they'll travel on the surface wherever free electrons form the reduction of oxygen and form the peroxides and super oxides and created holes oxidize the water and form the $\mathrm{OH} \cdot$; these generated species are extremely reactive and unstable and ultimately cause to the degradation of organic dyes. Many factors are influencing the Photocatalytic action on dyes, i.e., band gap, surface area, crystallinity, phase composition, surface hydroxyl density, size distribution, morphology, and particle size of the photocatalyst [30]. Prepared NiO NPs were taken as photocatalyst to check the methylene blue dye degradation under UV-light. In every 30 minutes, $2 \mathrm{~mm}$ of the aliquots sample solution was withdrawn and it was centrifuged and absorption of the samples was recorded. By measuring the change in intensity, we can calculate the degradation rate of dye at $\lambda$ $\max -664 \mathrm{~nm}$. 
A. Effect of Dye Concentration: The concentration of the dye is playing a crucial role in photocatalytic activity of $\mathrm{NiO}$ nanomaterials. Hence, so as to judge the optimum concentration of dye for promising photocatalytic activity, the experiment was carried out by changing the dye concentration of 5-20 ppm under catalytic loading constant $(100 \mathrm{mg}$ ) and UV light as in Fig.6. This clearly shows that as the dye concentration of $5-20 \mathrm{ppm}$ increases, the photocatalytic degradation is reduced by $80-20 \%$ and 20 $\mathrm{ppm}$ is the most effective concentration for dye degradation. Generally, as increases the dye concentration, the number of dye molecules is adsorbed on the surface of $\mathrm{NiO}$ nanoparticles, so the degradation rate decreases. On the other hand, adsorbed dye molecules were not degraded more rapidly because of the constant light intensity and catalyst loading.

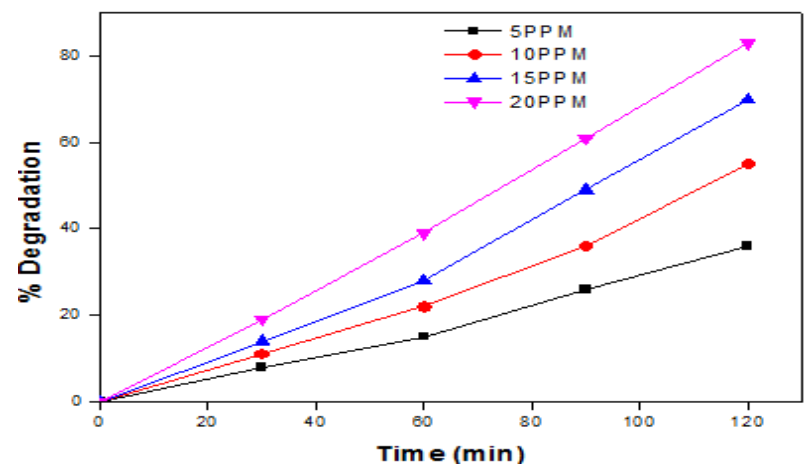

Fig. 6 Degradation MB with varying concentration of dye constant and catalyst load constant

The higher the dye concentration, the smaller the penetration power of light, which means that the photocatalytic decomposition is less at higher concentrations with less occurrence of hydroxyl groups and superoxide radicals [31].

B. Effect of Catalytic Load: Fig.7 represents the graph of MB degradation with varying catalyst load $(5-20 \mathrm{~mL})$ by maintaining the constant concentration of dye $(100 \mathrm{~mL}$ of 5 ppm). The data clearly reveals that as the catalyst load increases over 180 minutes, the rate of dye degradation increases from $70-100 \%$. This is because more active sites are available due to increased catalytic load [31].

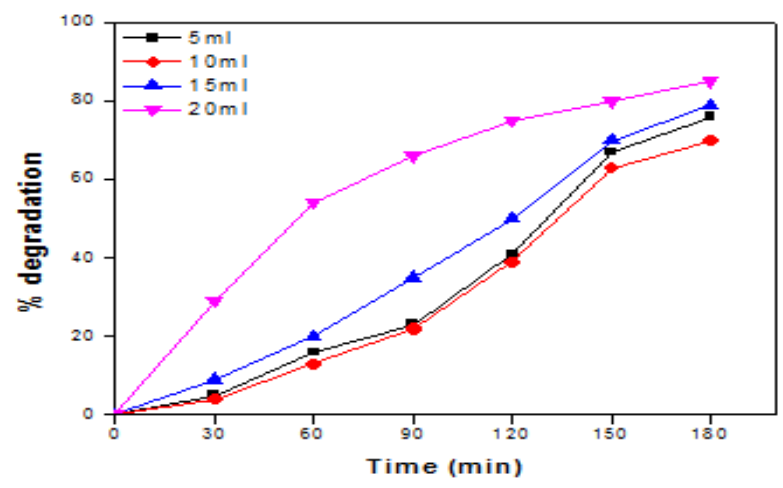

Fig. 7 Degradation of Methylene Blue with varying catalyst load
C. Effect of $p H$ : In order to see the optimum $\mathrm{pH}$ for the photolysis of the MB dye, experiments were conducted at completely different $\mathrm{pHs}$ ( 2 and 10 ) by maintaining the constant catalyst $(100 \mathrm{mg})$ and the dye concentration $(5 \mathrm{ppm})$, and the result represented in Fig. 8. This clearly shows that the MB degradation was effective in the basic medium [32, 33] with the very best degradation rate at $\mathrm{pH} 10$. The presence of an large number of $\mathrm{OH}^{-}$ions on the surface of the catalyst can produced less range of $\mathrm{OH}^{\cdot}$ radicals, that act as primary oxidizing agents and are responsible for the degradation of MB dye [3438].

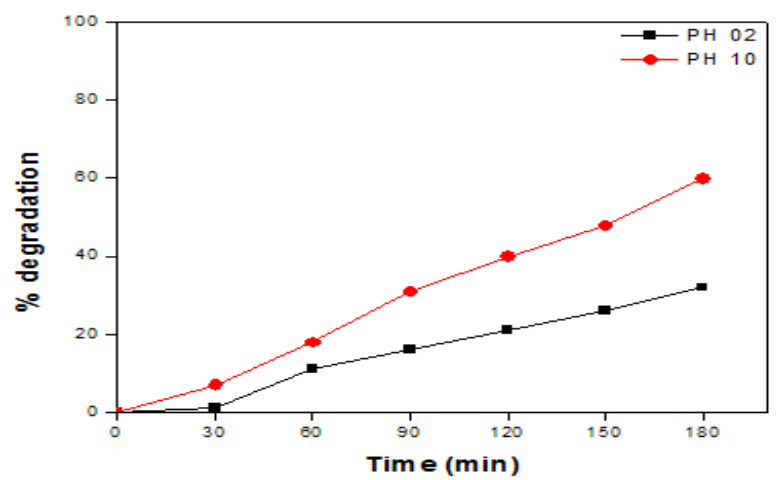

Fig. 8 Degradation of MB with varying $\mathrm{pH}$ of the solution and keeping the catalyst load and constant dye constant

D. Catalyst Recycling: To evaluate the stability of the photocatalyst, a recycling experiment was carried out to degradation the methylene blue dye (Fig. 9). The experiment was carried out with $100 \mathrm{mg}$ of catalyst and 100 $\mathrm{ml}$ of $5 \mathrm{ppm}$ dye. The decomposition potency of MB was nearly an equivalent for six cycles. This figure clearly shows a reduction in potency of nearly $80 \%$ altogether six cycles.

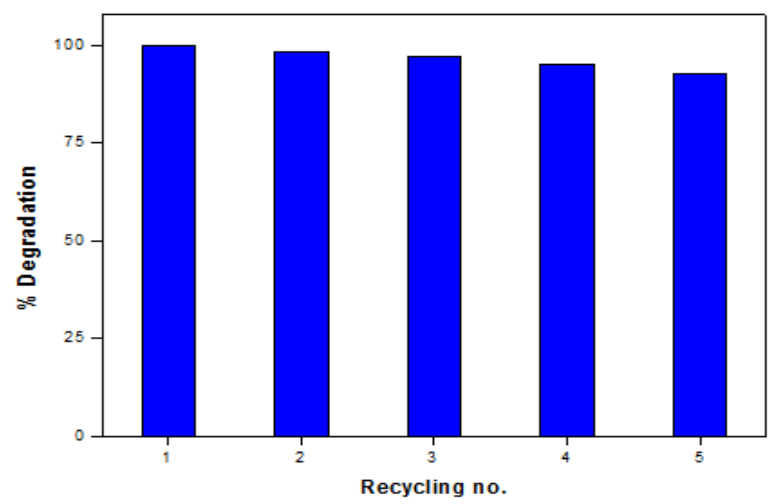

Fig. 9 Recycling of $10 \mathrm{mg}$ of catalyst and $100 \mathrm{ml}$ of $5 \mathrm{ppm}$ dye

E. Mechanism. Scheme: A schematic representation of the degradation of $\mathrm{MB}$ using $\mathrm{NiO}$ superstructure is shown below.

$$
\begin{gathered}
\mathrm{NiO}+\mathrm{h} v \rightarrow \mathrm{NiO}\left(\mathrm{h}^{+}{ }^{+}+\mathrm{e}_{\mathrm{cb}}^{-}\right) \\
\mathrm{OH}^{-} \text {ads }+\mathrm{h}^{+} \mathrm{vb}^{\rightarrow} \mathrm{OH}^{-} \text {ads }(\text { in basic medium }) \\
\mathrm{MB}+\mathrm{OH}_{\text {ads }} \rightarrow \text { dye degradation }
\end{gathered}
$$




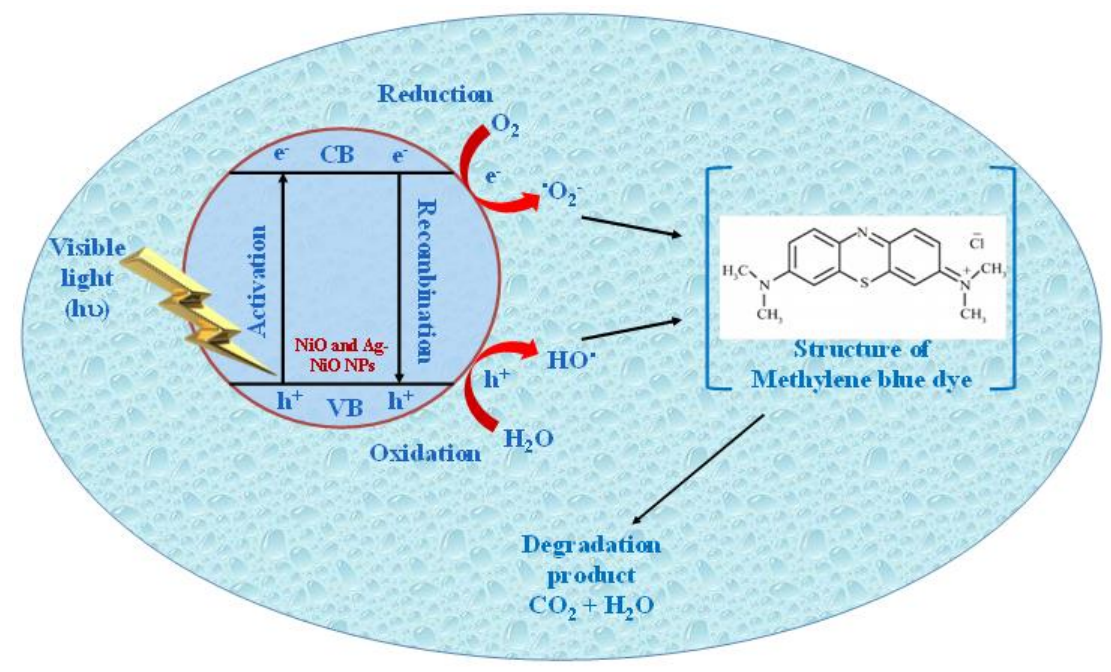

Fig. 10 Graphical representation for the mechanism of $\mathrm{NiO}$ under the irradiation of $\mathrm{UV}$-visible light

\section{PHOTOLUMINESCENCE STUDIES}

PL study is one among the helpful technique for notice the potency of charge carrier separation within the semiconductor [39]. The PL emission spectrum of $\mathrm{NiO}$ and $\mathrm{Ag}-\mathrm{NiO} \mathrm{NPs}$ were recorded in room temperature with an excitation wavelength of $271 \mathrm{~nm}$ represented in Fig. 10a. The pure $\mathrm{NiO}$ Nps provides a strong ultraviolet emission peak at $380 \mathrm{~nm}$. In case of $\mathrm{Ag}-\mathrm{NiO} \mathrm{Nps}$, the obtained PL emission intensity decreased and the resultant datas are in good agreement with the Stern-Volmer quenching represented in Fig. 11b.
This indicates the efficiency of high charge carrier separation in $\mathrm{Ag}-\mathrm{NiO} \mathrm{NP}_{\mathrm{s}}$. The emission peaks in visible region can be ascribed to bound excitons and defect states positioned at surface of nanostructured pure and doped $\mathrm{NiO}$ Nps respectively. Chromaticity coordinates are used to find luminous coloured objects and it can be estimated by Commission International De I'Eclairage (CIE) system. CIE chromaticity diagram of $\mathrm{NiO}$ and $\mathrm{Ag}-\mathrm{NiO}$ Nps represented in Fig. 10c reveals that both the material emit yellow light region [40].
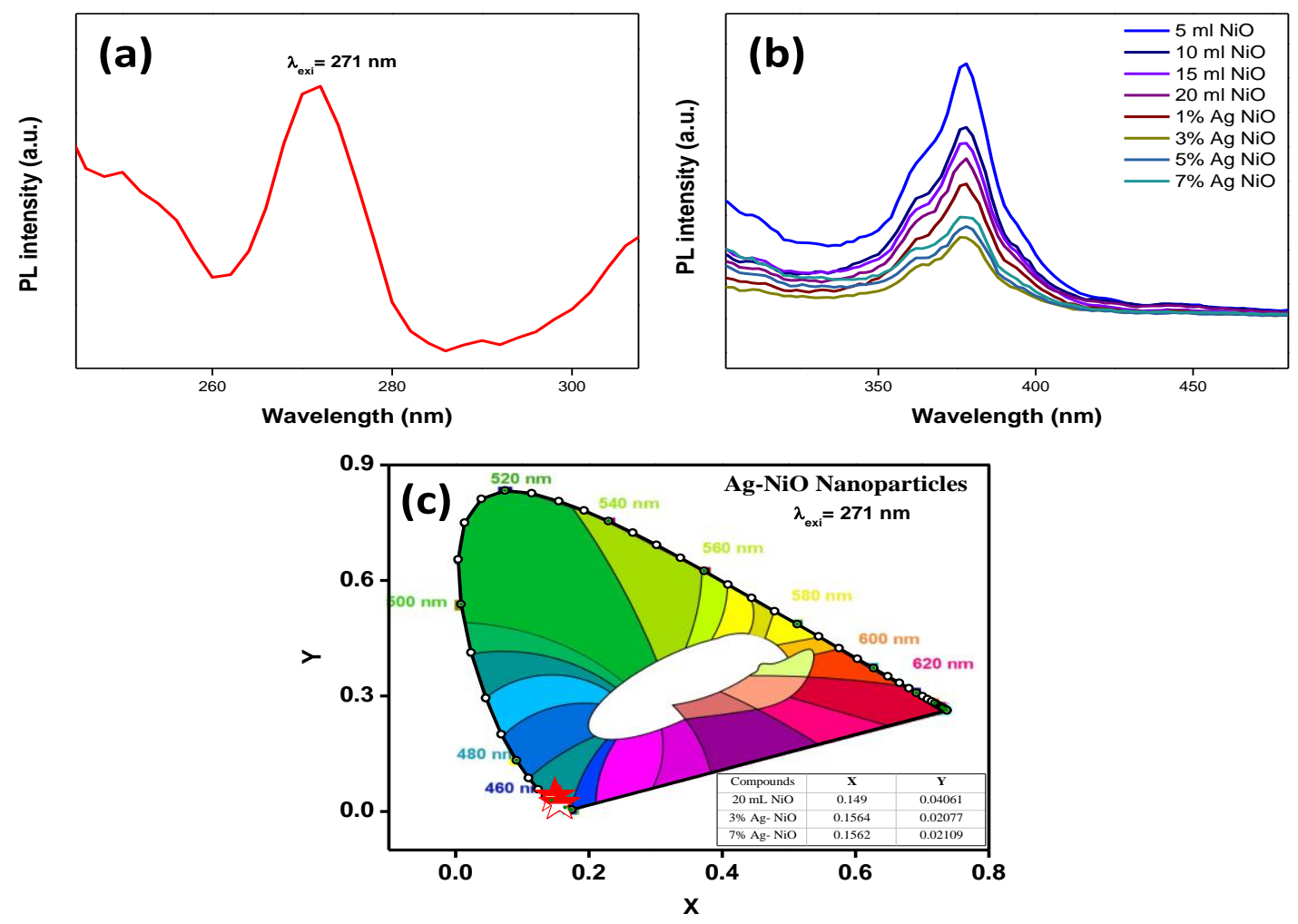

Fig. 11 PL spectrum of $\mathrm{NiO}$ and $\mathrm{Ag}-\mathrm{NiO}$ (a) excitation spectra (b) emission spectra (c) CIE diagram 


\section{CONCLUSION}

The $\mathrm{NiO}$ and Ag-NiO were synthesized by using Lycopodium Linn. Extract as fuel and employing by combustion method. The XRD pattern shows that $\mathrm{NiO}$ and $\mathrm{Ag}-\mathrm{NiO}$ nanoparticles belong to a cubic phase with an average crystallite size of $14.27 \mathrm{~nm}$ for $\mathrm{NiO}$ and $14.19 \mathrm{~nm}$ for $\mathrm{Ag}-\mathrm{NiO}$, respectively. The SEM image clearly shows that the Agglomeration of NPs. The TEM image shows that the particles are virtually agglomerated and crystalline. The prepared $\mathrm{NiO}$ and $\mathrm{Ag}-\mathrm{NiO} \mathrm{NPs}$ display 80 to $90 \%$ photodegradation activity over methylene blue dye. The photoluminescence study reveals that $\mathrm{NiO}$ and $\mathrm{Ag}-\mathrm{NiO}$ nano particles shown blue color emission.

\section{ACKNOWLEDGEMENT}

Mr. Udayabhanu gratefully acknowledge to CSIR-SRF (09/1204(0001)2018-EMR-I). Dr. GN thanks to DSTNanomission (SR/NM/NS-1262/2013) for financial support. Mr. Basavalingaiah thanks SIT for providing lab facilities.

\section{REFERENCES}

[1] M.A. Fox, and M.T. Dulay, "Heterogeneous photocatalysis", Chemical reviews, Vol. 93, No.1, pp. 341-357. 1993.

[2] A. Fujishima, and K. Honda, "Electrochemical photolysis of water at a semiconductor electrode", Nature, Vol. 238, No. 5358, pp. 37, Jul 1972.

[3] Y. Li, X. Fang, N. Koshizaki, T. Sasaki, L. Li, S. Gao, Y. Shimizu, Y. Bando, and D. Golberg, "Periodic $\mathrm{TiO}_{2}$ Nanorod Arrays with Hexagonal Nonclose-Packed Arrangements: Excellent Field Emitters by Parameter Optimization", Advanced Functional Materials, Vol. 19, No.15, pp. 2467-73, Aug 2009.

[4] Y. Qiu, K. Yan, H. Deng, and S. Yang, "Secondary branching and nitrogen doping of $\mathrm{ZnO}$ nanotetrapods: building a highly active network for photoelectrochemical water splitting", Nano letters, Vol. 12, No. 1, pp. 407-13, Dec 2011.

[5] K. M. Dooley, S. Y. Chen, and J. R. Ross, "Stable nickel-containing catalysts for the oxidative coupling of methane", Journal of catalysis, Vol. 145 No.2, pp.402-8, Feb 1994.

[6] H. X. Yang, Q. F. Dong, and X. H. Hu, "Preparation and characterization of $\mathrm{LiNiO}_{2}$ synthesized from $\mathrm{Ni}(\mathrm{OH})_{2}$ and $\mathrm{LiOH}$. $\mathrm{H}_{2} \mathrm{O}$ ”, Journal of Power Sources, Vol. 79, No. 2, Jun 1999.

[7] I. Hotový, J. Huran, L. Spiess, R. Čapkovic, and Š. Haščík, "Preparation and characterization of $\mathrm{NiO}$ thin films for gas sensor applications", Vacuum, Vol. 58, No. 2-3, pp. 300-7. Aug 2000.

[8] E. L. Miller, and R. E. Rocheleau, "Electrochemical behavior of reactively sputtered iron-doped nickel oxide", Journal of the Electrochemical Society, Vol. 144, No. 9, pp. 3072-7. Sep 1997.

[9] G. Wang, X. Lu, T. Zhai, Y. Ling, H. Wang, Y. Tong, and Y. Li, "Free-standing nickel oxide nanoflake arrays: synthesis and application for highly sensitive non-enzymatic glucose sensors", Nanoscale, Vol. 4, No. 10, pp. 3123-7. 2012.

[10] Y. Wang, J. Zhu, X. Yang, L. Lu, and X. Wang, "Preparation of $\mathrm{NiO}$ nanoparticles and their catalytic activity in the thermal decomposition of ammonium perchlorate", Thermochimica Acta, Vol. 437, No. 1-2, pp. 106-9. Oct 2005

[11] S. A. Makhlouf, F. T. Parker, F. E. Spada, and A. E. Berkowitz, "Magnetic anomalies in $\mathrm{NiO}$ nanoparticles", Journal of applied physics, Vol. 81, No. 8, pp. 5561-3. Apr 1997.

[12] X. Y. Deng, and Z. Chen, "Preparation of nano-NiO by ammonia precipitation and reaction in solution and competitive balance", Materials Letters, Vol. 58, No. 3-4, pp. 276-80. Jan 2004

[13] S. Chakrabarty, and K. Chatterjee, "Synthesis and characterization of nano-dimensional nickelous oxide $(\mathrm{NiO})$ semiconductor", J. Phys. Sci, Vol. 13, pp. 245, 2009.
[14] H. Yang, Q. Tao, X. Zhang, A. Tang, and J. Ouyang, "Solid-state synthesis and electrochemical property of $\mathrm{SnO}_{2} / \mathrm{NiO}$ nanomaterials", Journal of alloys and compounds, Vol. 459, No. 1-2, pp. 98-102, Jul 2008

[15] C. D. Guerra, A. Remn, J. A. Garcia, J. Piqueras, C. Díaz-Guerra, A. Remon, J. A. Garcia, and J. Piqueras, "Cathodoluminescence and photoluminescence spectroscopy of NiO”, Physica Status Solidi (a). Vol.163, No.2, pp. 497-503. Oct 1997

[16] J. Bahadur, D. Sen, S. Mazumder, and S. Ramanathan, "Effect of heat treatment on pore structure in nano-crystalline NiO: A small angle neutron scattering study", Journal of Solid State Chemistry, Vol. 181, No.5, pp. 1227-35, May 2008

[17] T. Nathan, A. Aziz, A. F. Noor, and S. R. Prabaharan, "Nanostructured $\mathrm{NiO}$ for electrochemical capacitors: synthesis and electrochemical properties", Journal of Solid State Electrochemistry, Vol. 12, No.7-8, pp. 1003-9. Aug 2008

[18] S. J. Peng, L. L. Li, H. T. Tan, Y. Z. Wu, R. Cai, H. Yu, X. Huang, P. N. Zhu, S. Ramakrishna, M. Srinivasan, and Q. Y. Yan, "Monodispersed Ag nanoparticles loaded on the PVP-assisted synthetic $\mathrm{Bi}_{2} \mathrm{O}_{2} \mathrm{CO}_{3}$ microspheres with enhanced photocatalytic and supercapacitive performances", Journal of Materials Chemistry A, Vol. 1, No.26, pp. 7630-8, 2013

[19] M. R. Hoffmann, S. T. Martin, W. Y. Choi, and D. W. Bahnemann, "Environmental applications of semiconductor photocatalysis", Chemical Reviews, Vol. 95, No. 1, pp. 69-96, 1995.

[20] X. Z. Li, and F. B. Li, "Study of Au/Au3+-TiO2 photocatalysts toward visible photooxidation for water and wastewater treatment", Environmental science \& technology, Vol. 35, No.11, pp. 2381-7, Jun 2001.

[21] Y. L. Pan, S. Z. Deng, L. Polavarapu, N. Y. Gao, P. Y. Yuan, and C. H. Xu, "Plasmon-enhanced photocatalytic properties of $\mathrm{Cu} 2 \mathrm{O}$ nanowire-Au nanoparticle assemblies", Langmuir, Vol. 28, No.33, pp.12304-10, Aug 2012.

[22] D. M. Schaadt, B. Feng, and E. T. Yu, "Enhanced semiconductor optical absorption via surface plasmon excitation in metal nanoparticles", Applied Physics Letters, Vol. 86, No.6, pp. 063-106, Feb 2005.

[23] H. Phattepur, G. B. Siddaiah, and N. Ganganagappa, "Synthesis and characterisation of mesoporous $\mathrm{TiO} 2$ nanoparticles by novel surfactant assisted sol-gel method for the degradation of organic compounds", Periodica Polytechnica Chemical Engineering, Vol. 63, No.1, pp. 85-95, 2019.

[24] S. Song, H. Yang, C. Zhou, J. Cheng, Z. Jiang, Z. Lu, and J. Miao, "Underwater superoleophobic mesh based on BiVO4 nanoparticles with sunlight-driven self-cleaning property for oil/water separation", Chemical Engineering Journal, Vol. 320, pp.342-51, Jul 2017.

[25] U. M. García-Pérez, S. Sepúlveda-Guzmán, and A. Martínez-De La Cruz, "Nanostructured BiVO4 photocatalysts synthesized via a polymer-assisted coprecipitation method and their photocatalytic properties under visible-light irradiation", Solid State Sciences, Vol. 14, No.3, pp. 293-8, Mar 2012.

[26] P. L. Hower, and T. K. Gupta, "A barrier model for $\mathrm{ZnO}$ varistors", Journal of Applied Physics, Vol. 50, No. 7, pp. 4847-55, Jul 1979.

[27] R. Wahab, S. G. Ansari, Y. S. Kim, H. K. Seo, G. S. Kim, G. Khang, and H. S. Shin, "Low temperature solution synthesis and characterization of $\mathrm{ZnO}$ nano-flowers", Materials Research Bulletin. Vol.42, No.9, pp.1640-8, Sep 2007.

[28] Udayabhanu, G. Nagaraju, H. Nagabhushana, R. B. Basavaraj, G. K. Raghu, D. Suresh, H. Rajanaika, and S. C. Sharma, "Green, nonchemical route for the synthesis of $\mathrm{ZnO}$ superstructures, evaluation of its applications toward photo-catalysis, photoluminescence, and bio-sensing", Crystal Growth \& Design. Vol.16, No.12, pp. 6828-40, Nov 2016.

[29] D. Suresh, P. C. Nethravathi, Udayabhanu, H. Rajanaika, H. Nagabhushana, and S. C. Sharma. "Green synthesis of multifunctional zinc oxide $(\mathrm{ZnO})$ nanoparticles using Cassia fistula plant extract and their photodegradative, antioxidant and antibacterial activities", Materials Science in Semiconductor Processing, Vol. 31, pp.446-54, Mar 2015.

[30] D. Suresh, P. C. Nethravathi, K. Lingaraju, H. Rajanaika, S. C. Sharma, and H. Nagabhushana, "EGCG assisted green synthesis of $\mathrm{ZnO}$ nanopowders: Photodegradative, antimicrobial and antioxidant activities", Spectrochimica Acta Part A: Molecular and Biomolecular Spectroscopy, Vol. 136, pp.1467-74, Feb 2015. 
[31] H. R. Madan, S. C. Sharma, D. Suresh, Y. S. Vidya, H. Nagabhushana, H. Rajanaik, K. S. Anantharaju, S. C. Prashantha, and P. S. Maiya, "Facile green fabrication of nanostructure $\mathrm{ZnO}$ plates, bullets, flower, prismatic tip, closed pine cone: their antibacterial, antioxidant, photoluminescent and photocatalytic properties", Spectrochimica Acta Part A: Molecular and Biomolecular Spectroscopy. Vol.152, pp. 404-16, Jan 2016.

[32] A. A. Khodja, T. Sehili, J. F. Pilichowski, and P. Boule, "Photocatalytic degradation of 2-phenylphenol on $\mathrm{TiO} 2$ and $\mathrm{ZnO}$ in aqueous suspensions", Journal of Photochemistry and Photobiology A: Chemistry, Vol. 141, No. 2-3, pp. 231-9, Jul 2001.

[33] S. P. Vinay, and N. Chandrasekhar, "Facile green chemistry synthesis of ag nanoparticles using areca catechu extracts for the antimicrobial activity and photocatalytic degradation of methylene blue dye", Materials Today: Proceedings, Vol. 9, pp.499-505, Jan 2019.

[34] S. P. Vinay, Udayabhanu, G. Nagarju, C. P. Chandrappa, and N. Chandrasekhar, "Enhanced photocatalysis, photoluminescence, and anti-bacterial activities of nanosize $\mathrm{Ag}$ : green synthesized via Rauvolfia tetraphylla (devil pepper)", SN Applied Sciences, Vol. 1, No. 4, pp. 477, May 2019

[35] J. Liqiang, S. Xiaojun, X. Baifu, W. Baiqi, C. Weimin, and F. Honggang, "The preparation and characterization of La doped $\mathrm{TiO} 2$ nanoparticles and their photocatalytic activity", Journal of Solid State Chemistry. Vol.177, No.10, pp. 3375-82, Oct 2004.

[36] A. Mills, R. H. Davies, and D. Worsley, "Water purification by semiconductor photocatalysis", Chemical Society Reviews, Vol. 22, No.6, pp. 417-25, Jan 1993.

[37] A. Lassoued, M. S. Lassoued, B. Dkhil, S. Ammar, and A. Gadri, "Photocatalytic degradation of methyl orange dye by $\mathrm{NiFe}_{2} \mathrm{O}_{4}$ nanoparticles under visible irradiation: effect of varying the synthesis temperature", Journal of Materials Science: Materials in Electronics, Vol. 29, No. 9, pp. 7057-67, May 2018.

[38] Q. Xiang, J. Yu, and P. K. Wong, "Quantitative characterization of hydroxyl radicals produced by various photocatalysts", Journal of Colloid and Interface Science, Vol. 357, No.1, pp. 163-7, May 2011.

[39] G. Nagaraju, H. Nagabhushana, D. Suresh, C. Anupama, G. K. Raghu, and S. C. Sharma, "Vitis labruska skins extract assisted green synthesis of $\mathrm{ZnO}$ super structures for multifunctional applications", Ceramics International, Vol. 43, No. 15, pp. 11656-67, Oct 2017.

[40] G. Nagaraju, S. A. Prashanth, M. Shastri, K. V. Yathish, C. Anupama, and D. Rangappa, "Electrochemical heavy metal detection, photocatalytic, photoluminescence, biodiesel production and antibacterial activities of $\mathrm{Ag}-\mathrm{ZnO}$ nanomaterial", Materials Research Bulletin, Vol. 94, pp. 54-63, Oct 2017. 